\title{
Plano Nacional de Educação e a educação básica em Municípios das Regiões Meio-Oeste e Planalto Serrano Catarinenses ${ }^{1}$
}

\author{
Ludimar Pegoraro \\ Mariangela Kraemer Lenz Ziede \\ Marialva Moog Pinto
}

\begin{abstract}
Resumo: O texto analisa o sistema de Educação Básica dos municípios pertencentes às Secretarias de Desenvolvimento Regional-SDRs de Santa Catarina, sediadas nos municípios de Caçador, Videira, Campos Novos e Curitibanos, compreendendo 26 municípios. As questões priorizadas pelo trabalho são: qual é a evolução do número de estudantes que frequentam as escolas de educação básica do Meio-Oeste e Planalto Serrano catarinenses, compreendendo as SDRs sediadas em Caçador, Videira, Campos Novos e Curitibanos? Como se dá a permanência desses estudantes nas diferentes etapas da educação básica? Através de pesquisa de campo realizada em 2014, o estudo mapeia a evolução de matrículas em cada SDR, município e escolas, identificando o número de estudantes em seus respectivos anos de escolaridade. Tomando o Plano Nacional de Educação (PNE/2014-2024) como base, a análise tem por finalidade elencar elementos que possibilitem a definição de políticas educacionais coletivas para a melhoria das instituições escolares, na perspectiva da permanência dos estudantes nas escolas, visando o desenvolvimento social nessa região. $\mathrm{Na}$ relação entre a educação, desenvolvimento sustentável e outros valores, ressalta-se a importância do desenvolvimento da consciência sobre a sustentabilidade do próprio desenvolvimento local e global.
\end{abstract}

Palavras-chave: Educação básica. Desenvolvimento regional. Meio-Oeste e Planalto Serrano Catarinenses. Santa

Catarina.

\section{National Education plan and basic education in the Municipalities of Midwest and Serrano Plateau Regions of Santa Catarina}

\begin{abstract}
The text analyzes the Basic Education system of the municipalities belonging to the Secretariats of Regional Development-SDRs of Santa Catarina, located in the municipalities of Caçador, Videira, Campos Novos and Curitibanos, comprising 26 municipalities. The questions prioritized by this work are: what is the evolution of the number of students attending the elementary schools of the Midwest and Planalto Serrano in Santa Catarina, comprising SDRs based in Caçador, Videira, Campos Novos and Curitibanos? How do these students stay in the different stages of basic education? Through field research conducted in 2014, the study maps the evolution of enrollments in each SDR, municipality and schools, identifying the number of students in their respective years of schooling. Taking the National Education Plan (PNE / 2014-2024) as a basis, the purpose of the analysis is to identify elements that allow the definition of collective educational policies for the improvement of school institutions, with a view to the permanence of students in schools, aiming at the development in this Brazilian region. In the relationship between education, sustainable development and other values, the importance of developing awareness about the sustainability of local and global development itself is emphasized.
\end{abstract}

Keywords: Basic education. Regional development. Midwest and Serrano plateau regions of Santa Catarina State, Brazil.

\footnotetext{
${ }^{1}$ Universidade Alto Vale do Rio do Peixe; Prefeituras Municipais das Agencias de Desenvolvimento Regional envolvidas na pesquisa.
}

Quaestio, Sorocaba, SP, v. 19, n. 3, p. 651-667, dez. 2017. 


\section{Introdução}

A educação é um processo social, é desenvolvimento. Não é a preparação para a vida, é a própria vida.

John Dewey

Não é difícil constatar que a temática da educação se apresenta como um conjunto complexo e desafiador de questões nas sociedades letradas contemporâneas. Está associada a aprendizagens imprescindíveis à qualidade de vida individual e coletiva. A educação ainda perpassa por questões fundamentais, como: os valores como a cidadania, democracia, política, ética, trabalho, (co)existência; os espaços escolares, principalmente os fatores administrativos e de infraestrutura, que podem interferir na qualidade do ensino, abrindo ou fechando possibilidades de acesso e permanência dos estudantes nas salas de aula; os financiamentos, envolvendo várias dimensões, desde a manutenção das escolas aos salários dos professores; e as questões pedagógicas atinentes aos processos de construção de conhecimentos, inovação, invenção, etc. que qualificam o ensino e a aprendizagem. Considerando as particularidades do nosso tempo e entendendo que a problemática educativa está encarnada nas fases históricas das diferentes sociedades, ressalta-se a importância do desenvolvimento da consciência sobre a sustentabilidade $^{2}$ do próprio desenvolvimento ${ }^{3}$ local e global.

Em função da pertinência da relação entre a educação, desenvolvimento sustentável e outros valores, nossa análise será desenvolvida a partir de estudos de campo realizados no MeioOeste e Planalto Serrano de Santa Catarina, contemplando as Secretarias de Desenvolvimento Regional - SDRs, sediadas em Caçador, Videira, Campos Novos e Curitibanos, compreendendo 26 municípios. Para a coleta dos dados, inicialmente, foi realizada a identificação da região com os respectivos contatos e, ainda, na sequência foi elaborada planilha que possibilitasse a coleta

\footnotetext{
${ }^{2}$ A palavra sustentável tem origem no latim "sustentare", que significa sustentar, apoiar, conservar. O conceito de sustentabilidade está normalmente relacionado com uma mentalidade, atitude ou estratégia que é ecologicamente correta, e viável no âmbito econômico, socialmente justa e com uma diversificação cultural (SIGNIFICADO..., 2015).

${ }^{3}$ Desenvolvimento sustentável é o desenvolvimento capaz de suprir as necessidades da geração atual, sem comprometer a capacidade de atender as necessidades das futuras gerações. É o desenvolvimento que não esgota os recursos para o futuro (WWF-BRASIL, 2017).

Quaestio, Sorocaba, SP, v. 19, n. 3, p. 651-667, dez. 2017.
} 
dos dados que interessavam. A pesquisa pretendeu avaliar as transformações em andamento a partir das matrículas e permanência dos estudantes nas escolas de educação básica dessa região específica.

Procurando dar sentido e direcionamento às análises, priorizamos as seguintes questões: Qual é a evolução do número de estudantes que frequentam as escolas de educação básica do Meio-Oeste e Planalto Serrano catarinenses, compreendendo as SDRs sediadas em Caçador, Videira, Campos Novos e Curitibanos? Como se caracteriza a permanência dos estudantes nas diferentes etapas desse nível de ensino?

Para dar visibilidade às análises, após contemplar aspectos legais como forma de institucionalização de direitos, faremos aportes dos dados sistematizados nesta pesquisa com as metas e estratégias do Plano Nacional de Educação - PNE/2014-2024 (BRASIL, 2014).

\section{Educação Básica e o Plano Nacional de Educação (PNE/2014-2024)}

A Educação Básica no Brasil ganhou contornos complexos, especialmente nos últimos anos. Analisá-la não é tarefa das mais fáceis exatamente porque os determinantes desse fenômeno são múltiplos, dentre os quais destacamos: o financiamento, a qualidade, a permanência, a repetência, a desigualdade econômica e a infraestrutura. É possível considerar, também, que seu direcionamento legal é objeto de políticas ou convênios associados a organismos internacionais, como a Emenda Constitucional n ${ }^{\text {0 59, de }} 11$ de novembro de 2009 (BRASIL, 2009), que estabeleceu a obrigatoriedade da escolaridade para o período dos 4 até aos 17 anos, compreendido como o da Educação Básica, e que, inclusive, coloca o país entre aqueles que possuem maior período de escolaridade para este nível de ensino.

A Constituição Federal de 1988 é um marco importante no que se refere às conquistas coletivas de direitos no Brasil, pois representa, de fato, a democratização da sociedade brasileira. Como não poderia ser diferente e por tratar de questões decisivas para o desenvolvimento das sociedades, a educação, em todos os seus níveis, teve o seu merecido destaque na Carta Magna. Atualmente, parte significativa dos países do mundo defende e garante em seus documentos legais o direito de acesso e permanência dos seus cidadãos à educação escolar básica por entendêla necessária e fundamental para o exercício da política cidadã e também para possibilitar a 
continuidade da formação profissional em nível superior. O tempo de escolaridade nesse nível pode variar de 9 a 14 anos entre diferentes países.

Na Constituição Brasileira de 1988 (BRASIL, 1988), este preceito está presente no seu art. 205, que assevera que "a educação, direito de todos e dever do Estado e da família, será promovida e incentivada com a colaboração da sociedade, visando ao pleno desenvolvimento da pessoa, seu preparo para o exercício da cidadania e sua qualificação para o trabalho".

A educação escolar, entendida e definida como um direito, passa a ser bem público que envolve todos os segmentos da sociedade. Conforme afirma Cury (2011, p. 2), a educação é:

[...] um bem público de caráter próprio por implicar a cidadania e seu exercício consciente, por qualificar para o mundo do trabalho, por ser gratuita e obrigatória no ensino fundamental, por ser gratuita e progressivamente obrigatória no ensino médio, por ser também dever do Estado na educação infantil.

Seguindo as orientações das Diretrizes Curriculares Nacionais da Educação Básica, do Ministério da Educação (MEC), a Educação Básica é "um dos fundamentos do projeto de Nação que estamos construindo. A formação escolar é o alicerce indispensável e condição primeira para o exercício pleno da cidadania e o acesso aos direitos sociais, econômicos, civis e políticos" (BRASIL, 2013, p. 4).

Analisando estas definições, é possível considerar que o direito à educação parte do reconhecimento de que o saber sistemático, na perspectiva de Cury (2011), é mais do que uma importante herança cultural. Ele possibilita que o cidadão se torne capaz de interagir cognitivamente para participar dos destinos da sociedade, colaborando para sua transformação. Assim, o conhecimento sistemático passa a ser uma condição sine qua non para o desenvolvimento das sociedades. Ele se fortalece pela ação ou pelo saber-fazer ${ }^{4}$ responsável e consciente dos profissionais formados nos diferentes níveis de escolarização ${ }^{5}$.

\footnotetext{
${ }^{4}$ A característica principal do saber-fazer, na perspectiva aqui tratada, está associada às habilidades motoras e ao conhecimento necessário para o exercício de uma profissão. O profissional não pode ser apenas um executor de tarefas no exercício de sua profissão, mas necessita da consciência política para dimensionar as consequências de sua ação. Piaget (1973) identificou três tipos de conhecimento que o indivíduo constrói: o conhecimento físico que é desenvolvido pela ação direta do sujeito sobre o objeto; o conhecimento lógico-matemático que é fruto das reflexões, nominal e prático que leva à conceituação e o conhecimento social que é aquele formado através da interação com outras pessoas na sociedade.

${ }^{5}$ A escolarização no Brasil está dividida em dois níveis, o básico e o superior. No básico residem os conhecimentos necessários à formação cidadã. No superior residem os conhecimentos relacionados à formação profissional, incluindo, também, aqueles que devem priorizar a inserção social do profissional.
}

Quaestio, Sorocaba, SP, v. 19, n. 3, p. 651-667, dez. 2017. 
Outro documento importante, complementar à Constituição Federal, marco regulatório da educação brasileira, é a Lei de Diretrizes e Bases da Educação Nacional (LDB), Lei $\mathrm{n}^{\circ}$ 9.394/1996 (BRASIL, 1996). Nesse documento foi instituída e fortalecida a ideia de que a educação básica é direito do cidadão e dever do Estado e compreende, conforme o art. 21, três etapas sequenciais de escolarização: a Educação Infantil, o Ensino Fundamental e o Ensino Médio. Este art. 21 da LDB foi reformulado possibilitando avanços na efetivação de direitos através da Emenda Constitucional no 59/2009 (BRASIL, 2009), que define como obrigatória a escolaridade dos 4 aos 17 anos, isto é, período que compreende exatamente as três etapas da Educação Básica. A LDB, no art. 22, também estabelece as finalidades dessas etapas escolares, afirmando que "a educação básica tem por finalidades desenvolver o educando, assegurar-lhe a formação comum indispensável para o exercício da cidadania e fornecer-lhe meios para progredir no trabalho e em estudos posteriores" (BRASIL, 1996).

Sem dúvida que essa conceituação é relevante e muito consistente no que se refere ao sentido social da Educação Básica. Ela contempla alguns aspectos inovadores para a época, considerando a trajetória histórica do Brasil que, em décadas anteriores (1964-1985), havia passado por um regime recessivo-ditatorial ou por um período histórico de ditadura civilempresarial-militar, e que por séculos também foi elitista e seletivo, negando à maioria dos cidadãos a possibilidade de frequentar, de forma sistemática, uma instituição escolar. Pensando na perspectiva de Cury (2002, p. 170), “a ideia de desenvolvimento do educando nestas etapas que formam um conjunto orgânico e sequencial é o do reconhecimento da importância da educação escolar para os diferentes momentos dessas fases da vida”. Este conceito, de certa forma, reforça as finalidades da educação brasileira, já mencionadas anteriormente, presentes no art. 205 da Constituição Federal.

Tomando essas etapas a partir de uma perspectiva evolutiva, é possível considerar que a Educação Infantil constitui a base da Educação Básica, o Ensino Fundamental o tronco e o Ensino Médio o acabamento (CURY, 2002, p. 170). Somente a partir do olhar sobre o todo tornase possível um entendimento da importância das partes. Uma problemática, presente nessa questão da Educação Básica como efetivação dos direitos, é identificar os caminhos que o país, considerando suas dimensões e diversidades, encontrou para efetivar essa política em todas as suas regiões. Para essa análise, retomamos a Constituição Federal que, já no seu art. $1^{\circ}$, reconhece o Brasil como uma República Federativa formada pela união indissolúvel dos estados, municípios 
e o Distrito Federal. Essa compreensão é reforçada pela Lei n ${ }^{\circ} 13.005$, de 25 de julho de 2014 (BRASIL, 2014), que aprova o Plano Nacional de Educação (PNE) e define, para alcançar as metas e implementar as estratégias do Plano, no seu Art. $7^{\circ}$, um regime de colaboração entre a União, os Estados, o Distrito Federal e os Municípios.

Demonstrando coerência entre os principais documentos que definem as políticas do país, o documento referência da CONAE/2014, eixo I, “O Plano Nacional de Educação e o Sistema Nacional de Educação: organização e regulação", item 27, orienta que é fundamental o pacto federativo, construído na colaboração e coordenação entre os entes federados, distribuindo responsabilidades e repartindo competências, acrescentando a necessidade da participação dos sistemas de ensino para que seja garantido o direito à educação e para que o processo seja coroado pela qualidade (BRASIL, 2014).

Dentre esses documentos legais importantes que direcionam a educação básica brasileira cabe aqui destacar as diretrizes do PNE (2014-2024) diretamente relacionadas a este nível ensino, quais sejam:I - erradicação do analfabetismo;

II - universalização do atendimento escolar;

III - superação das desigualdades educacionais, com ênfase na promoção da cidadania e na erradicação de todas as formas de discriminação;

IV - melhoria da qualidade da educação;

V - formação para o trabalho e para a cidadania, com ênfase nos valores morais e éticos em que se fundamenta a sociedade;

VI - promoção do princípio da gestão democrática da educação pública;

VII - promoção humanística, científica, cultural e tecnológica do País;

VIII - estabelecimento de meta de aplicação de recursos públicos em educação como proporção do Produto Interno Bruto-PIB, que assegure atendimento às necessidades de expansão, com padrão de qualidade e equidade;

IX - valorização dos(as) profissionais da educação;

$\mathrm{X}$ - promoção dos princípios do respeito aos direitos humanos, à diversidade e à sustentabilidade socioambiental (BRASIL, 2014).

As diretrizes do PNE (2014-2014) reforçam também o compromisso político da nação no sentido de tornar a Educação Básica acessível - e de qualidade - a todas as etapas desse nível de ensino.

Entendendo que essas abordagens apresentam aspectos importantes sobre os fundamentos legais pertinentes à Educação Básica, o próximo passo é estabelecer, numa perspectiva objetiva, uma relação entre algumas metas e estratégias do PNE com a realidade escolar dos municípios do Meio-Oeste e Planalto Serrano catarinenses, entendendo que é nos municípios, unidade menor dos entes federados, que a vida acontece. O direcionamento do trabalho será o de responder as questões anteriormente apresentadas à luz dos dados a serem elencados. 


\section{Educação Básica em municípios das regiões Meio-Oeste e Planalto Serrano de Santa Catarina}

Para a análise de aspectos referentes à Educação Básica nas Regiões Meio-Oeste e Planalto Serrano catarinenses, em especial sobre a permanência dos estudantes nas escolas de Educação Básica, é necessário sublinhar um pouco mais aquilo que foi anteriormente abordado sobre a organização político-estrutural do país. Essa estrutura política parte do princípio democrático da importância da junção de forças entre a União, Distrito Federal, estados e municípios, a partir de um sistema integrado, para a efetivação de políticas públicas de educação; neste particular, de Educação Básica. Entretanto, considerando a objetividade das ações e a pertinência dos processos educacionais, é possível observar que é nos municípios que a vida acontece e é a partir deles que o presente estudo ganha a sua relevância maior.

Se a organização política é um fator indispensável para fluxo e desenvolvimento de ações articuladas, independente dos níveis, instâncias e instituições, ao olharmos para o mundo educacional escolar, cabe também ressaltar que, numa perspectiva dialética, não há como separar os princípios educacionais dos da sociedade, uma vez que a primeira se fortalece e ganha sentido na vida coletiva, pública. Por isso, o presente estudo ganha relevância quando é analisado quantitativa e qualitativamente, contextualizando os dados, demonstrando a repercussão dos mesmos para o desenvolvimento da região a partir das suas unidades escolares, onde, de fato, as ações se concretizam.

O estado de Santa Catarina, de forma semelhante ao Brasil, tem um modelo de gestão governamental descentralizado, partilhado. Foram instituídos pelo governo Luiz Henrique da Silveira, em 2003, 28 SDRs, que mais tarde passaram a ser 30. No atual governo de João Raimundo Colombo esse número foi elevado para 36. Essas SDRs foram instituídas com a finalidade de "transferir parte do planejamento e das ações de governo para instâncias mais próximas do cidadão" (SANTA CATARINA, 2003, p. 8). Para a análise das questões da Educação Básica, selecionamos 4 dessas secretarias, tomando como referência a Universidade Alto Vale do Rio do Peixe (UNIARP), a instituição de educação superior mais antiga da região e que tem, desses municípios, a procedência da maior parte dos seus estudantes de graduação.

Para dar melhor visibilidade dessa região no contexto estadual, na Figura 1 apresentamos o mapa do Estado destacando as SDRs selecionadas para o estudo. 
Figura 1 - Mapa do estado de Santa Catarina destacando as SDRs objetos da pesquisa

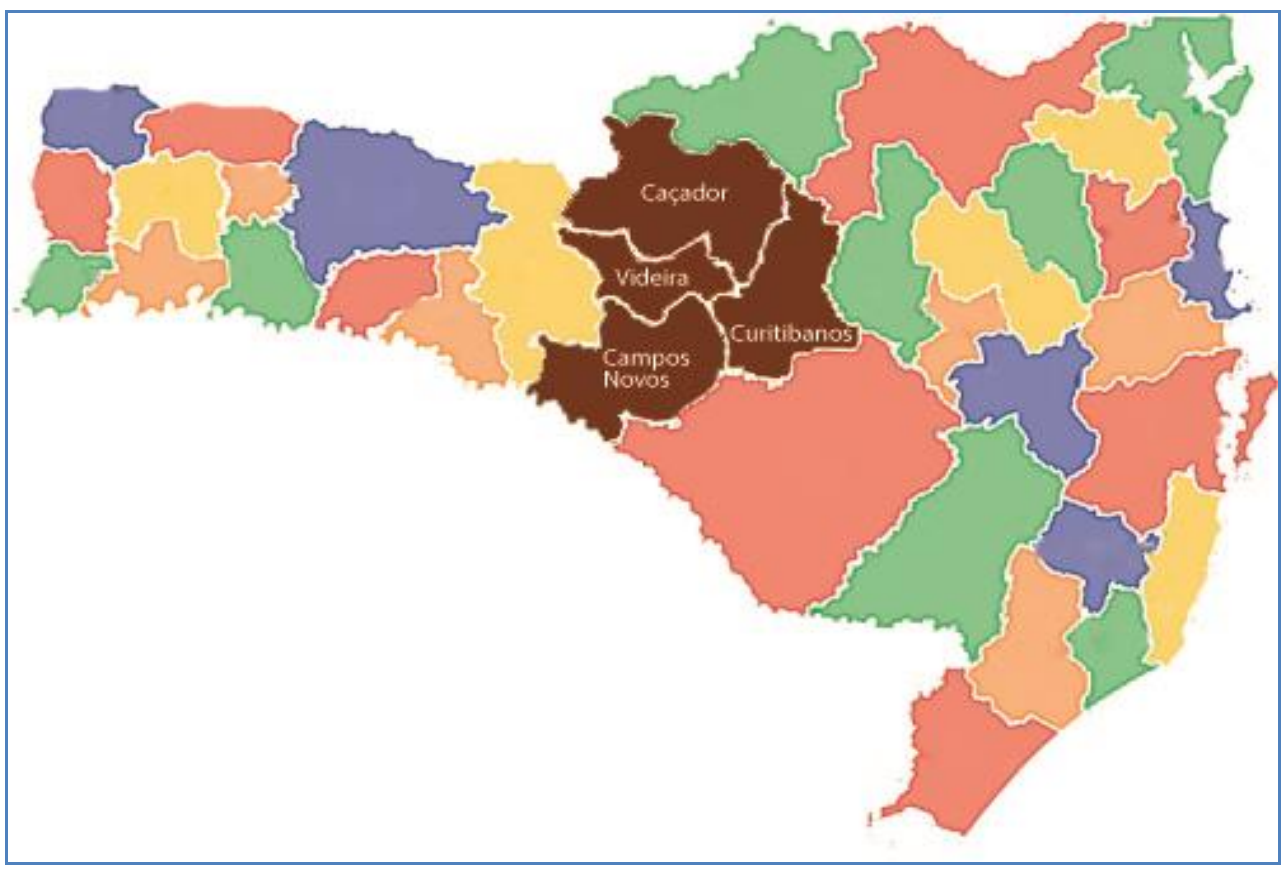

Nota: Adaptado pelos autores.

Fonte: SANTA CATARINA (Estado). Um caminho para a democracia participativa. Florianópolis: Cidade Futura, 2003.

Essas SDRs estão localizadas no Meio-Oeste e Planalto Serrano do Estado de Santa Catarina, praticamente no centro do Estado. Os municípios pertencentes a essas secretarias possuem características semelhantes, tanto na questão climática e colonizatória, quanto nas questões socioeconômicas. A economia tem no agronegócio seu grande potencial, entretanto a atividade varia de região para região. Enquanto as SDRs de Caçador e Curitibanos estão focadas em culturas de extração vegetal, mais fortemente vinculadas aos reflorestamentos de pinus elliottii, também se destacando no cultivo de tomate, cebola, alho, uva e outras variedades de legumes, verduras e frutas, as SDRs de Videira e Campos Novos, além de algumas atividades praticamente semelhantes às das SDRs anteriores, no que se refere ao cultivo de cereais, verduras, legumes e frutas, têm suas principais atividades econômicas vinculadas a um sistema de produção integrado entre indústria e proprietários rurais, visando à criação de aves e suínos atividades essas ligadas às principais empresas de agronegócio alimentício do país, e, também, à produção de cereais a partir de um sistema institucionalizado e bem organizado de cooperativas.

Para identificar os municípios estudados, apresenta-se a tabela que indica, por SDR, a relação dos municípios pesquisados, o número de habitantes em cada município, o Índice de 
Desenvolvimento Humano por Município (IDHM), o número de estudantes matriculados no Ensino Fundamental e Médio e o percentual da população que esses estudantes representam.

Tabela 1- Relação das SDRs e respectivos municípios com número de habitantes, IDHM, número de estudantes que frequentaram a escola no ensino fundamental e médio no ano de 2014 e porcentagem da população que está na escola

\begin{tabular}{|c|c|c|c|c|c|}
\hline SDR & Municípios & Habitantes & IDHM & E.E.F.M. & $\%$ \\
\hline \multirow{7}{*}{ Caçador } & Caçador & 70.762 & 0,735 & 12.857 & 18,16 \\
\hline & Calmon & 3.387 & 0,622 & 882 & 26,04 \\
\hline & Lebon Régis & 11.838 & 0,649 & 2.356 & 19,90 \\
\hline & Macieira & 1.826 & 0,662 & 353 & 19,33 \\
\hline & Matos Costa & 2.839 & 0,657 & 544 & 19,16 \\
\hline & Rio das Antas & 6.143 & 0,697 & 1.044 & 16,99 \\
\hline & Timbó Grande & 7.167 & 0,659 & 1.689 & 23,56 \\
\hline \multirow{7}{*}{ Campos Novos } & Addon Batista & 2.653 & 0,694 & 450 & 16,96 \\
\hline & Brunópolis & 2.850 & 0,661 & 581 & 20,38 \\
\hline & Campos Novos & 32.824 & 0,742 & 6.127 & 18,66 \\
\hline & Ibiam & 1.945 & 0,725 & 302 & 15,52 \\
\hline & Monte Carlo & 9.312 & 0,643 & 1.797 & 19,29 \\
\hline & Vargem & 2.808 & 0,629 & 549 & 19,55 \\
\hline & Zortéa & 2.991 & 0,761 & 605 & 20,22 \\
\hline \multirow{5}{*}{ Curitibanos } & Curitibanos & 37.748 & 0,721 & 6.995 & 18,53 \\
\hline & Frei Rogério & 2.474 & 0,682 & 530 & 21,42 \\
\hline & Ponte Alta do Norte & 3.303 & 0,689 & 643 & 19,46 \\
\hline & Santa Cecília & 15.775 & 0,698 & 3.122 & 19,79 \\
\hline & São Cristóvão do Sul & 5.012 & 0,665 & 764 & 15,24 \\
\hline \multirow{7}{*}{ Videira } & Arroio Trinta & 3.502 & 0,764 & 517 & 14,76 \\
\hline & Fraiburgo & 34.553 & 0,731 & 6.369 & 18,43 \\
\hline & Iomerê & 2.739 & 0,795 & 367 & 13,39 \\
\hline & Pinheiro Preto & 3.147 & 0,777 & 528 & 16,77 \\
\hline & Salto Veloso & 4.301 & 0,784 & 636 & 14,78 \\
\hline & Tangará & 8.674 & 0,737 & 1.360 & 15,67 \\
\hline & Videira & 47.188 & 0,764 & 7.910 & 16,76 \\
\hline \multicolumn{2}{|l|}{ Total Geral } & 327.761 & & 59.877 & 18,28 \\
\hline
\end{tabular}

Fonte: ATLAS do Desenvolvimento Humano Brasil. 2013. Disponível em: <http://www.atlasbrasil.org.br/2013/pt/o_atlas/idhm/>. Acesso em: 15 fev. 2015.

Nota: Tabela organizada e adaptada pelos autores.

Analisando a Tabela 1, constata-se que os municípios sede das SDRs são os que possuem maior população, e Caçador, no quadro das 4 microrregiões, é o município que possui o maior 
número de habitantes. Entretanto, no contexto do estado, esses mesmos municípios-sede podem ser considerados de médio porte e os demais, pequenos.

Quando analisamos o IDH, que é medido levando em consideração longevidade, ${ }^{6}$ educação ${ }^{7}$ e renda, ${ }^{8}$ esse índice é representado por um número que varia de 0 a 1 , sendo que, quanto mais próximo de 1, maior o IDH, foi possível observar que há fatores intervenientes que aproximam e diferenciam essas microrregiões.

$\mathrm{Na}$ análise da tabela 1, ainda, foi possível perceber que:

\section{a) Quanto ao IDHM - Longevidade}

Observando a fonte dos dados, um aspecto que aproxima essas regiões e que eleva o IDHM é a longevidade. Praticamente todos os municípios têm índices altos ou muito altos no que se refere à expectativa de vida, inclusive alguns classificados entre os melhores do Brasil, como era o caso de Arroio Trinta. Outro fator que os aproxima é o crescimento dos índices de educação nos últimos 20 anos. No princípio dos anos de 1990, muitos desses municípios classificavam-se como muito baixos, inclusive alguns deles situando-se entre os piores do Brasil, como era o caso de Calmon. Entretanto, nos últimos anos, os avanços foram significativos em praticamente todos eles, mas, mesmo considerando o salto qualitativo, alguns ainda não conseguiram passar dos 0,600 pontos, o que os coloca numa condição de baixa classificação.

\footnotetext{
6 "Vida longa e saudável é medida pela expectativa de vida ao nascer, calculada por método indireto, a partir dos dados dos Censos Demográficos do IBGE. Esse indicador mostra o número médio de anos que uma pessoa nascida em determinado município viveria a partir do nascimento, mantidos os mesmos padrões de mortalidade" (ATLAS..., 2013).

7 "Acesso a conhecimento é medido por meio de dois indicadores. A escolaridade da população adulta é medida pelo percentual de pessoas de 18 anos ou mais de idade com ensino fundamental completo - tem peso 1 . O fluxo escolar da população jovem é medido pela média aritmética do percentual de crianças de 5 a 6 anos frequentando a escola, do percentual de jovens de 11 a 13 anos frequentando os anos finais do ensino fundamental, do percentual de jovens de 15 a 17 anos com ensino fundamental completo e do percentual de jovens de 18 a 20 anos com ensino médio completo - tem peso 2. A medida acompanha a população em idade escolar em quatro momentos importantes da sua formação. Isso facilita aos gestores identificar se as crianças e jovens estão nas séries adequadas nas idades certas. A média geométrica desses dois componentes resulta no IDHM Educação. Os dados são do Censo Demográfico do IBGE” (ATLAS..., 2013).
}

8 "Padrão de vida é medido pela renda municipal per capita, ou seja, a renda média dos residentes de determinado município. É a soma da renda de todos os residentes, dividida pelo número de pessoas que moram no município inclusive crianças e pessoas sem registro de renda. Os dados são dos Censos Demográficos do IBGE" (ATLAS..., 2013).

Quaestio, Sorocaba, SP, v. 19, n. 3, p. 651-667, dez. 2017. 


\section{b) Quanto ao IDHM - Renda}

Outro aspecto marcante e diferenciador entre as SDRs e seus respectivos municípios é o fator renda. A desigualdade socioeconômica é marcante na maior parte das microrregiões. Ela acaba por interferir, em algumas regiões, significativamente na continuidade dos estudos de grande parte dos estudantes.

Conforme observado anteriormente, os fatores socioeconômicos que identificam essas SDRs, no caso de Caçador e Curitibanos, é a cultura extrativista, e Campos Novos e Videira é a cultura do agronegócio integrado. Esses fatores socioeconômicos fazem com que esses municípios sejam distintos no que se refere à distribuição de renda e educação.

Para as SDRs de Caçador e Curitibanos, observando o IDHM, constata-se que, com exceção das sedes, que apresentam índices altos, os demais municípios estão classificados como médios. Entretanto, observando a Base de dados do IDHM, esses municípios têm classificação diminuída nos quesitos renda e educação. As sedes se situam na condição de médio e os respectivos municípios na condição de baixos. É também nesses aspectos que a maior parte desses municípios fica classificada entre as mais baixas do estado. A SDR de Campos Novos apresenta características diversas; sem dúvida que as condições socioeconômicas têm a ver com a trajetória histórica de cada município, entretanto, a região passa por um processo acelerado de mudanças com a migração das agroindústrias alimentícias para a região. Já o Município de Videira, por desenvolver a cultura do agronegócio há mais tempo, mantendo importante parcela da população do campo em atividades integradas, apresenta um cenário diferenciado dentro contexto aqui analisado. Todos os municípios pertencentes a SDR de Videira apresentam índices altos de desenvolvimento.

\section{c) Quanto ao IDHM - Educação}

Outro fator importante a ser observado é o percentual da população que frequenta a escola. Quanto menor o IDHM, maior o número percentual de estudantes na escola. Uma hipótese explicativa para essa situação é que esse fenômeno está associado ao número de filhos no interior das famílias. Entretanto, é bom ressaltar que, para uma análise conclusiva da questão, seriam necessárias outras pesquisas com enfoque mais específico.

Independentemente das condições individuais de desenvolvimento das SDRs e seus respectivos municípios no que se refere ao acesso à educação, apresenta-se a Tabela 2 que Quaestio, Sorocaba, SP, v. 19, n. 3, p. 651-667, dez. 2017. 
identifica, por SDR, o número de instituições escolares pesquisadas e suas respectivas instâncias de controle.

Tabela 2 - Número de instituições escolares pesquisadas por SDRs e por redes de ensino

\begin{tabular}{l|c|c|c}
\hline \multirow{2}{*}{ SDR } & \multicolumn{3}{c}{ Redes } \\
\cline { 2 - 4 } & Municipal & Estadual & Particular \\
\hline Caçador & 45 & 18 & 9 \\
\hline Campos Novos & 29 & 14 & 2 \\
\hline Curitibanos & 24 & 14 & 5 \\
\hline Videira & 30 & 20 & $\mathbf{1 8}$ \\
\hline Total Geral & $\mathbf{1 2 8}$ & $\mathbf{6 6}$ & 2 \\
\hline
\end{tabular}

Fonte: Elaborada pelos autores.

Nas 4 SDRs e respectivos municípios, foram pesquisadas 212 unidades escolares do Ensino Fundamental e Médio. Dessas unidades, 194 são públicas, 91,5\%, sendo 128 municipais e 66 estaduais, e tão somente 18 privadas, 8,5\%. Entre essas instituições privadas, a grande maioria delas é de caráter filantrópico, isto é, de caráter público e com gestão privada, diferenciando-se das estritamente particulares. Todas as escolas privadas estão localizadas nos municípios sedes das SRDs e atuam nos diferentes níveis da Educação Básica. Algumas oferecem apenas os anos iniciais do Ensino Fundamental, outras oferecem as duas etapas e mais o Ensino Médio e outras oferecem apenas os anos finais do Ensino Fundamental.

Com relação às escolas públicas, todos os estudantes dos anos iniciais do Ensino Fundamental estão sob a coordenação dos municípios; entretanto, os estudantes dos anos finais ainda não foram assumidos integralmente por essa instância governamental. A transferência dessa responsabilidade, da instância governamental estadual para os municípios, está associada à questão do financiamento. ${ }^{9}$ Já a oferta do ensino médio é totalmente atendida pela Rede Estadual.

Dentre os municípios pesquisados, apenas Campos Novos, Calmon, Timbó Grande e Matos Costa ainda mantêm o modelo de escola multisseriada. Nas escolas multisseriadas são ministradas aulas para alunos de diferentes idades e ano de escolaridade ao mesmo tempo. Este modelo de escola ainda é muito importante para algumas regiões do Brasil. Entretanto, em Santa

\footnotetext{
9 No ano de 1983, foi aprovada a Emenda Calmon, pela qual os mínimos orçamentários para a educação foram alterados, cabendo à União a aplicação de pelo menos 13\% e aos Estados, Distrito e Municípios, 25\% da receita dos impostos e transferências (MOTA, 2007, p. 9). Esses percentuais, estabelecidos no sentido de garantir o acesso, permanência e qualidade da educação para os estudantes dos municípios, se mostraram insuficientes, gerando debates e discordâncias com relação à municipalização da educação.
}

Quaestio, Sorocaba, SP, v. 19, n. 3, p. 651-667, dez. 2017. 
Catarina, quando a maior parte da população morava no meio rural, ele era representativo, mas, com o processo migratório e a ampliação das oportunidades de acesso às escolas na cidade, realizou-se um trabalho de nucleação, incrementando assim o acesso por meio da ampliação ou implementação do transporte escolar.

Cabe ressaltar, ainda, a importância da presença das instituições públicas estatais nessas regiões. Embora com algumas limitações estruturais, tanto o Estado como os municípios têm procurado atender às demandas dos estudantes nas diferentes etapas desse nível de ensino, fortalecendo o papel do Estado na implementação das políticas de acesso à Educação Básica.

Para observar esse trabalho realizado tanto pelo Estado, como pelos municípios e instituições privadas, apresenta-se a Tabela 3, com o número de estudantes do ensino fundamental, por SDR e por ano de escolaridade.

Tabela 3 - Número de estudantes do Ensino Fundamental, por ano de escolaridade e por SDR

\begin{tabular}{|c|c|c|c|c|c|c|c|c|c|}
\hline \multirow{3}{*}{ SDR } & \multicolumn{9}{|c|}{ Número de estudantes por ano de escolaridade } \\
\hline & \multicolumn{9}{|c|}{ Ensino fundamental } \\
\hline & $1^{\circ}$ & $2^{\circ}$ & $3^{\circ}$ & $4^{\circ}$ & $5^{\circ}$ & $6^{\circ}$ & $7^{\circ}$ & $8^{\circ}$ & $9^{\circ}$ \\
\hline Caçador & 1687 & 1701 & 1646 & 1776 & 1988 & 2274 & 1935 & 1664 & 831 \\
\hline Campos Novos & 795 & 837 & 1011 & 989 & 1004 & 959 & 1044 & 1130 & 182 \\
\hline Curitibanos & 1099 & 1029 & 1135 & 1088 & 1138 & 1360 & 1236 & 1147 & 473 \\
\hline Videira & 1396 & 1456 & 1598 & 1512 & 1435 & 1492 & 1700 & 1620 & 984 \\
\hline Total geral & 4977 & 5023 & 5390 & 5365 & 5565 & 6085 & 5915 & 5561 & 2470 \\
\hline
\end{tabular}

Fonte: Elaborada pelos autores.

A meta 2, do PNE (2014-2014) (BRASIL, 2014, p. 9), estabelece:

Universalizar o ensino fundamental de 9 (nove) anos para toda a população de 6 (seis) a 14 (quatorze) anos e garantir que pelo menos $95 \%$ (noventa e cinco por cento) dos alunos concluam essa etapa na idade recomendada, até o último ano de vigência deste PNE.

Observando a Tabela 3, pode-se identificar que a meta 2, do PNE, no que se refere aos 9 anos, vem sendo plenamente atendida. Entretanto, com base somente nesses dados, não é possível quantificar se o acesso está universalizado e muito menos se os concluintes atingem os 95\% pretendidos pela referida meta. 
Analisando a evolução das matrículas, o maior número de estudantes se concentra no $6^{\circ} \mathrm{e}$ $7^{\circ}$ anos. Esse índice - como hipótese - pode estar associado às reprovações. Entretanto, também pode ser constatado que há redução de matrículas do $8^{\circ}$ para o $1^{\circ}$ ano. Essa redução pode estar associada à diminuição do número de filhos uma vez que nos primeiros anos trabalha-se com índices próximos dos $100 \%$ e, nos anos finais desse nível o índice diminui significativamente.

Outro aspecto observado se refere ao $9^{\circ}$ ano. A redução do número de estudantes está associada à ampliação para nove anos de Ensino Fundamental. Como alguns municípios, segundo os dados coletados na pesquisa, não adotaram imediatamente a política definida pelo MEC, somente a partir do ano de 2015 é que essa meta será alcançada. Contudo, nos próximos anos do Ensino Médio, isto é, de 2015 a 2017, haverá, consecutivamente, um número menor de estudantes em cada ano letivo.

Há que se considerar nesses números um fator que interfere nas matrículas e permanência dos estudantes nas escolas. Esse fator está associado às culturas sazonais de tomate, pimentão, alho, maçã entre outras, que movimentam famílias de outras regiões nos períodos das safras.

Os dados da tabela 3 chamam a atenção para a redução do número de estudantes do $8^{\circ}$ ano para o $1^{\circ}$ ano. Embora nessa tabela geral isso não apareça, nas planilhas onde foram registradas as informações das escolas por município é possível perceber que há casos em que essa redução, nesses oito anos, chega a 48\%. Analisando os dados na perspectiva do crescimento populacional esses números são preocupantes, pois há um processo involutivo.

Para observar a evolução desses períodos de escolarização, apresenta-se, a seguir, na Tabela 4, o número de estudantes matriculados no ensino médio, por SDR e por ano de escolaridade.

Tabela 4 - Número de estudantes do ensino médio, por SDR e por ano de escolaridade

\begin{tabular}{l|c|c|c}
\hline \multirow{2}{*}{ SDR } & \multicolumn{2}{c}{ Número de estudantes por ano de escolaridade no } \\
& \multicolumn{2}{c}{ Ensino Médio } \\
\cline { 2 - 4 } & $1^{\mathbf{0}}$ & $2^{\mathbf{0}}$ & $3^{\mathbf{0}}$ \\
\hline Caçador & 1955 & 1320 & 984 \\
\hline Campos Novos & 1037 & 652 & 771 \\
\hline Curitibanos & 1018 & 727 & 604 \\
\hline Videira & 1910 & 1369 & 1215 \\
\hline Total Geral & $\mathbf{5 9 2 0}$ & $\mathbf{4 0 6 8}$ & $\mathbf{3 5 7 4}$ \\
\hline
\end{tabular}

Fonte: Elaborada pelos autores. 
A meta 3 do PNE (2014-2014) (BRASIL, 2014, p. 10) determina: "Universalizar, até 2016, o atendimento escolar para toda a população de 15 (quinze) a 17 (dezessete) anos e elevar, até o final do período de vigência deste PNE, a taxa líquida de matrículas no ensino médio para $85 \%$ (oitenta e cinco por cento)."

Levando em consideração a Tabela 4 e o teor da meta 3 do PNE (2014 - 2024), é possível afirmar que há consonância entre essas informações. Existe nessa região disponibilidade infraestrutural para o atendimento da demanda estudantil do Ensino Médio. Entretanto, quando analisados os dados, observa-se que a meta não está sendo plenamente atendida quando se refere à taxa líquida dos $85 \%$ (oitenta e cinco por cento) pretendidos para esse nível do ensino. O índice de permanência dos estudantes do $1^{\circ}$ (primeiro) ano para o $3^{\circ}$ (terceiro) cai significativamente. Na SDR de Caçador o índice de desistentes chega a 49,66\%. Na SDR de Campos Novos, esse índice cai significativamente, passando para 25,65\%. Na SDR de Curitibanos, novamente, o índice sobe, atingindo 40,66\%. Em Videira, o índice também cai, ficando em 36,38\%.

Como se pode observar a partir dos percentuais contidos na Tabela 4, os índices são muito elevados considerando a meta 3 do PNE. Se retomarmos a Tabela $\mathrm{n}^{\circ}$ 1, referente ao IDHM, vê-se que as SDRs que possuem menor IDHM - Caçador e Curitibanos - são as que apresentam maior índice de desistência dos estudantes do Ensino Médio. Isso, de certa forma, fortalece a ideia de que as condições socioeconômicas interferem concretamente na permanência dos estudantes nas escolas.

\section{Considerações}

Revisitando as análises apresentadas, podemos considerar que a Educação Básica, como suporte ou fundação da sociedade brasileira, apresenta uma forma de organização legal que pode repercutir em importantes mudanças ou melhorias com relação ao acesso, sucesso e permanência dos estudantes nas escolas.

Em Santa Catarina, a descentralização do governo em microrregiões possibilita estudos mais focados e pormenorizados de cada região e/ou município, podendo assim ser desenvolvidas políticas públicas que viabilizem, com maior rapidez, o atendimento de necessidades, em especial daquelas relacionadas à educação básica, que ficam sob a coordenação do estado e dos municípios, nos termos da legislação vigente. 
As SDRs estudadas, no que concerne ao IDHM, apresentam realidades distintas. O desenvolvimento socioeconômico, a partir das culturas desenvolvidas, produzem fatores sociais que interferem no desenvolvimento social e, nesse particular, na permanência dos estudantes nas escolas. As SDRs de Caçador e Curitibanos, com culturas semelhantes, baseadas em extrativismo vegetal, juntamente com seus municípios, apresentam altos índices de evasão escolar e baixo índice de renda per capita. Considerando os dados levantados e a realidade dessas regiões, cabe ao Governo do Estado desenvolver, através dessas SDRs, trabalhos orientados de política públicas que impactem no desenvolvimento social, bem como desenvolvas mecanismos que incentivem a permanência dos estudantes nas escolas.

Retomando o objetivo deste estudo, que foi o de elencar elementos que possibilitem a definição de políticas educacionais coletivas visando à melhoria das instituições escolares na perspectiva da permanência dos estudantes nas escolas visando o desenvolvimento social na região, podemos considerar que a realidade dessas microrregiões, em especial as SDRs de Caçador e Curitibanos, que destoam do contexto da Região Sul, e entendendo fundamental o pacto federativo para o atendimento de questões específicas da Educação Básica, cabem ações conjuntas, União, estado e municípios, no sentido de definirem políticas públicas educacionais direcionadas para esses espaços e que resultem em melhorias, no menor prazo possível, da matrícula e permanência, sem falar, obviamente, da qualidade do processo formativo dos estudantes.

\section{Referências}

ATLAS do Desenvolvimento Humano Brasil. 2013. Disponível em:

<http://www.atlasbrasil.org.br/2013/pt/o_atlas/idhm/>. Acesso em: 15 fev. 2015.

BRASIL. CONAE. O PNE na articulação do Sistema Nacional de Educação: participação popular, cooperação federativa e regime de colaboração. Brasília: Ministério da Educação, 2014.

BRASIL. Constituição da república federativa do Brasil. Brasília: Senado Federal, 1988.

BRASIL. Lei de diretrizes e bases da Educação Nacional. Lei no 9.394/96. Brasília: MEC, 1996.

BRASIL. Ministério da Educação. Secretaria de Educação Básica. Secretaria de Educação Continuada, Alfabetização, Diversidade e Inclusão. Conselho Nacional da Educação. Diretrizes curriculares nacionais gerais da educação básica. Brasília: MEC, SEB, DICEI, 2013.

BRASIL. Planejando a próxima década: conhecendo as 20 metas do Plano Nacional de Educação. Brasília: Ministério da Educação, Secretaria de Articulação com os sistemas de Ensino (MEC/SASE), 2014. 
BRASIL. Presidência da República. Emenda Constitucional No 59, de 11 de novembro de 2009. Disponível em: <http://www.planalto.gov.br/ccivil_03/constituicao/emendas/emc/emc59.htm>. Acesso em: 20 mar. 2016.

BRASIL. Presidência da República. Lei no 13.005, de 25 de junho de 2014. Aprova o Plano Nacional de Educação (PNE). Disponível em: 〈http://planalto.gov.br/ccivil_03/_Ato2011-2014/Lei/L13005.htm>. Acesso em: 10 fev. 2015.

CURY, Carlos Roberto Jamil. A educação básica no Brasil. Educ. Soc., Campinas, v. 23, n. 80, p. 168200, set. 2002. Disponível em: <http://www.cedes.unicamp.br>. Acesso em: 5 fev. 2015.

CURY, Carlos Roberto Jamil. O direito à educação: um campo de atuação do gestor educacional na escola. Brasília: MEC, 2011. Disponível em: <http://escoladegestores.mec.gov.br/site/8biblioteca/pdf/jamilcury.pdf >. Acesso em: 12 fev. 2015.

MOTA, Ademar Benedito R. da. A história da municipalização do ensino no Brasil. In: JORNADA DO HISTEDBR, 7., 2007, Campo Grande, MT. Anais... Campo Grande: UNIDERP, 2007. Disponível em: <http://www.histedbr.fe.unicamp.br/acer_histedbr/jornada/jornada7/03trab-autor-A.htm>. Acesso em: 20 maio 206.

PIAGET, Jean. Biologia e conhecimento: ensaio sobre as relações entre as regulações orgânicas e os processos cognoscitivos. Petrópolis: Vozes, 1973.

SANTA CATARINA (Estado). Um Caminho para a democracia participativa. Florianópolis: Cidade Futura, 2003.

SIGNIFICADO de sustentabilidade. Disponível em: 〈http://www.significados.com.br/sustentabilidade/>. Acesso em: 20 fev. 2015.

WWF-BRASIL. O que é desenvolvimento sustentável? Disponível em: <http://www.wwf.org.br/natureza_brasileira/questoes_ambientais/desenvolvimento_sustentavel/>. Acesso em: 18 jul. 2017.

Ludimar Pegoraro - Universidade Alto Vale do Rio do Peixe (UNIARP). Caçador | SC | Brasil. Contato: pegoraro1963@hotmail.com

Mariangela Kraemer Lenz Ziede - Universidade Alto Vale do Rio do Peixe (UNIARP). Caçador | SC | Brasil. Contato: mariangelaziede@gmail.com

Marialva Moog Pinto - Universidade Alto Vale do Rio do Peixe (UNIARP). Caçador | SC | Brasil. Contato: marialvamoog@ hotmail.com 